\title{
Fatores limitantes da gestão dos produtos florestais não-madeireiros na APA de Guaratuba
}

\author{
Limiting factors in the management of non-timber forest products in \\ Guaratuba's EPA
}

\begin{abstract}
Ana Paula Donicht Fernandes', Vitor Afonso Hoeflich ${ }^{\mathrm{II}}$, Ivan Crespo Silva ${ }^{\mathrm{III}}$, Mara Freire Rodrigues de Souza ${ }^{\mathrm{IV}}$
\end{abstract}

\begin{abstract}
Resumo
O "acesso livre" aos produtos florestais não-madeireiros vem gerando uma série de questões críticas para o governo e para o setor florestal. Nesse contexto, a exploração sustentável dos produtos florestais não-madeireiros é apontada como uma importante estratégia para a conservação da biodiversidade e também para a geração de renda e qualidade de vida das populações rurais. O município de Guaratuba é composto em sua totalidade pela Área de Proteção Ambiental (APA) de Guaratuba, onde vivem populações tradicionais que têm o extrativismo intrínseco aos seus costumes. Assim, este trabalho visa identificar os fatores limitantes da gestão dos produtos florestais não-madeireiros da Mata Atlântica do litoral do Estado do Paraná. A coleta de dados foi baseada em entrevistas com 70 famílias moradoras da APA de Guaratuba, das quatro unidades de gestão: Morro Grande, Estrada do Castelhano, Caovi-Cubatão e Baia de Guaratuba. Os dados foram submetidos à análise SWOT. Como principais resultados, cada comunidade mostrou-se heterogênea no seu sistema produtivo de uso e comercialização de produtos florestais não-madeireiros. A avaliação das fortalezas e fraquezas dos sistemas de produção avaliados indicam que a região de estudo se mostra adequada para o desenvolvimento de atividades com produtos não-madeireiros. Conclui-se que a sustentabilidade da atividade não madeireira na região está longe de ser alcançada. Programas de conservação devem reconhecer que existe, nas Áreas de Proteção Ambiental, um alto grau de ocupação humana em que oportunidades de capacitação, superação de carência de recursos econômicos e básicos de saúde e infraestrutura devem ser sanados com urgência. Dessa forma, a atividade não madeireira, na forma como está sendo gerida, não pode ser considerada como estratégia de desenvolvimento para as comunidades, no entanto, se observadas as questões levantadas neste estudo, podem tornar-se atrativas.
\end{abstract}

Palavras-chave: Análise SWOT; Comunidade tradicional; Fatores críticos de sucesso

\footnotetext{
Engenheira Florestal, Dra., Universidade Federal Rural da Amazônia, Campus Capitão Poço, Tv. Pau Amarelo, s/n, Vila Nova, CEP 68650-000, Capitão Poço (PA), Brasil. anapauladfernandes@yahoo.com.br (ORCID: 0000-0002-3644-9825)

II Engenheiro Agrônomo, D.Sc., Professor do Departamento de Economia Rural e Extensão, Universidade Federal do Paraná, Rua dos Funcionários, 1540, Cabral, CEP 80035-050, Curitiba (PR), Brasil, vitor.ufpr@gmail.com (ORCID: 0000-0003-0561-3933)

III Engenheiro Florestal, Dr., Professor do Departamento de Ciências Florestais, Universidade Federal do Paraná, Rua dos Funcionários, 1540, Cabral, CEP 80035-050, Curitiba (PR), Brasil. ivancrespo@uol.com.br (ORCID: 0000-0001-5171-2073)

IV Engenheira Florestal e Advogada, Dra., Pesquisadora Autônoma, Rua Professora Maria Jose Godoy, n. 94, sala 201, CEP 80.520-220, Curitiba (PR), Brasil. maraambiental@hotmail.com (ORCID: 0000-0001-9221-1611)
} 


\begin{abstract}
The "free access" to non-timber forest products raises several critical issues for both government and industry. In this way, a sustainable management of non-timber forest products is referred as an important strategy for the biodiversity conservation as well for income generation and a life quality enhancer of rural populations. The municipality of Guaratuba is encompassed by the Guaratuba Environmental Protection Area (EPA), where the traditional population lives and carries out the extractivism activity that is intrinsic to their customs. Therefore, this work aims to identify the limiting factors for the management of the nontimber forest products in the Atlantic Forest biome, on the coast of the state of Paraná. The data collection was based on interviews with 70 families living in Guaratuba's EPA, from the four management units: Morro Grande, Estrada do Castelhano, Caovi-Cubatão and Baia de Guaratuba. The data was submitted to SWOT analysis. Each community is heterogeneous in its productive system of use and commercialization of non-timber forest products. The evaluation of the strengths and weaknesses of the evaluated production systems indicates that the region of study is suitable for the development of activities with non-timber forest products. It is concluded that the sustainability of non-timber activity in the region is far from being achieved. Conservation programs should recognize that in the Environmental Protection Areas there is a high degree of human occupation, where opportunities for training, overcoming the lack of economic and basic health and infrastructure resources must be solved as a matter of urgency. Thus, non-timber activity, in the way it is managed, cannot be considered as a development strategy for the communities, however, if the issues raised in this study are addressed, the activity can become attractive.
\end{abstract}

Keywords: SWOT analysis; Traditional community; Critical success factors

\title{
Introdução
}

No Brasil, a Mata Atlântica presente no município de Guaratuba é protegida em sua totalidade pela Área de Proteção Ambiental (APA) de Guaratuba, que engloba todo o município de Guaratuba e parte dos municípios de Matinhos, Tijucas do Sul, São José dos Pinhais e Morretes (PARANÁ, 2016). No entanto, devido aos conflitos fundiários, iniciados na década de 1960, a criação e efetivação das áreas protegidas e a especulação imobiliária decorrente do turismo, a população tradicional, que tem seu modo de vida baseado na cultura caiçara, vem sofrendo restrições de uso do território e, até mesmo, tem findado suas atividades tradicionais, com significativas mudanças no patrimônio natural e cultural (SILVEIRA-JUNIOR; BOTELHO, 2011).

Para Ferreira (2010), dentre os principais fatores causadores dessas restrições está a falta de participação efetiva das comunidades rurais com atividades extrativistas no conselho gestor da APA, a ciência sobre a realização de reuniões, dificuldades de locomoção, falta de ambiente favorável a sua manifestação e principalmente a exclusão durante o processo de criação da APA. No entanto, para uma ação sustentável, o extrativismo precisa ser uma opção para as populações locais; quando essas populações estão oprimidas, sofrendo pressões ambientais ou conflitos agrários, o extrativismo torna-se sua única opção e não ocorrerá de forma sustentável (FERREIRA, 2010). Assim, são imprescindíveis estudos que promovem mapear os fatores que limitam as famílias extrativistas a promover a sustentabilidade das comunidades extrativistas do litoral do Paraná.

Nesse contexto, a exploração sustentável dos produtos florestais não-madeireiros sejam eles provenientes de florestas nativas, sistemas agroflorestais ou plantações - constitui uma importante estratégia para a conservação da biodiversidade, bem como para a geração de renda e qualidade de vida das populações rurais (CARVALHAES et al., 2008). O comércio de produtos florestais não-madeireiros (PFNMs) vem sendo considerado como estratégia capaz de conciliar tanto o desenvolvimento socioeconômico de comunidades tradicionais habitantes de áreas naturais, quanto a conservação ambiental (BRITES; MORSELLO, 2008).

Dessa forma, a análise SWOT constitui um importante instrumento para avaliar as 
contribuições do extrativismo no estabelecimento de cenários sustentáveis nas comunidades tradicionais e também para realizar uma avaliação de situações externas, que podem estar associadas ao uso insustentável desses recursos. Diante desse cenário, neste estudo buscouse identificar os fatores limitantes dos sistemas de produção e comercialização dos produtos florestais não-madeireiros identificados na APA de Guaratuba, litoral da Mata Atlântica do estado do Paraná.

\section{Materiais e métodos}

\section{Área de estudo}

A Mata Atlântica é o bioma mais ameaçado do Brasil. O município de Guaratuba, foco deste trabalho, possui uma área de 132.680 hectares, dos quais $100 \%$ são considerados como área do Bioma Mata Atlântica, segundo a lei 11.428 de 2006 (SOS Mata Atlântica e Instituto Nacional de Pesquisas Espaciais, 2014). Ainda segundo o mesmo estudo, 80\% do município de Guaratuba é composto de vegetação natural e quase sua totalidade está inserida nos limites da Área de Proteção Ambiental de Guaratuba. Atualmente, a população caiçara paranaense remanescente distribui-se em 35 comunidades rurais, englobando aproximadamente 4.000 pessoas e 600 famílias (ANACLETO et al., 2007).

Na APA de Guaratuba, encontram-se as duas grandes unidades de relevo que ocorrem no litoral, a Planície Litorânea ou Costeira e a Serra do Mar. Em função desses aspectos e do ambiente em que se encontram, ocorrem na APA de Guaratuba distintas formações vegetais: desde manguezais, que são formações bastante especializadas ao meio e de baixa diversidade, até florestas mais complexas, riquíssimas em espécies e formas de vida (SONDA, 2002). As principais tipologias encontradas na APA de Guaratuba são as Formações Pioneiras de Influência Marinha, Fluviomarinha e Fluvial e as Formações das Terras Baixas e Submontana da Floresta Ombrófila Densa.

\section{Caracterização da amostra}

A amostragem probabilística é fortemente condicionada pela existência prévia de um cadastro sem falhas. Considerando-se a inexistência do pré-requisito indicado, optou-se pela amostragem não-probabilística por conveniência, que é aquela em que a seleção dos elementos da população para compor a amostra depende ao menos em parte do julgamento do pesquisador ou do entrevistador no campo.

As entrevistas semiestruturadas combinam questões abertas e fechadas permitindo buscar respostas necessárias para a compreensão de perguntas presentes na pesquisa de forma espontânea. Para Oliveira (2009), as entrevistas semiestruturadas são as que mais possibilitam a compreensão e o estudo de questões "nesse ambiente".

Assim, dada a extensão territorial que a pesquisa pretende cobrir, optou-se pela definição de uma fração fixa de $10 \%$ das famílias por unidade de gestão, gerando um número total de 70 famílias entrevistadas. A coleta de dados foi baseada em entrevistas com famílias moradoras da APA de Guaratuba, das quatro unidades de gestão: Morro Grande, Estrada do Castelhano, Caovi-Cubatão e Baia de Guaratuba. A coleta dos dados foi conduzida durante os meses de agosto, setembro e outubro de 2016 com o apoio logístico/institucional das equipes da EMATER Paraná e do Instituto de Florestas do Paraná em Guaratuba. 


\section{Construção da Matriz SWOT}

Os passos adotados para a construção da matriz SWOT são apresentados a seguir:

1. Identificação dos fatores externos e internos (Tabela 1), por meio de revisão bibliográfica em trabalhos desenvolvidos na mesma área de estudo (FERREIRA, 2010; CHITSONDZO; SILVA, 2013; NEGRELLE, et al., 2014; WALDHOFF, 2014).

\section{Tabela 1 - Fatores internos e externos identificados na APA de Guaratuba}

Table 1 - Internal and external factors identified in Guaratuba's EPA

\begin{tabular}{ll}
\hline & Fatores Internos \\
\hline - Mão de obra familiar & \\
- Conhecimento tradicional & - Quantidade ideal de extração \\
- Venda na propriedade & - Conhecimento de manejo \\
- Recurso abundante & - Recurso financeiro e humano \\
- Necessidade de pequenas áreas & - Inserção do produto no mercado \\
- Identificação dos produtores com a floresta & - Participação/engajamento \\
- Diversificação da renda & - Infraestrutura \\
- Relacionamento com o vizinho & \\
\hline & Fatores Externos \\
\hline - Recurso sustentável & - Legislação não-consolidada \\
- Selo verde & - Comércio ilegal \\
- Impacto reduzido & - Extinção de espécies \\
- Parcerias & - Erosão do conhecimento tradicional \\
- Preservação da cultura & - Oportunidade de emprego em outras atividades \\
- Manutenção da família no campo & - Criação da APA \\
- Novos produtos & - Assistência técnica \\
- Agricultura orgânica & - Estudos sobre capacidade de manejo das espécies \\
- Agregação de valor & - Dificuldade de acesso às propriedades \\
- Empreendedorismo comunitário & - Preço injusto \\
- Políticas públicas de incentivo ao desenvolvimento rural & - Regularização fundiária \\
- Capacitação técnica de boas práticas de manejo & \\
\hline
\end{tabular}

Fonte: Autores (2018)

2. Esses fatores foram transformados em perguntas fechadas para alocação dos indicadores em Pontos Fracos e Fortes (Fatores internos) e Oportunidades e Ameaças (Fatores externos);

3. Para complementação desses indicadores, perguntas abertas foram elaboradas e agrupadas em conjuntos de respostas similares;

4. Construção das matrizes de avaliação dos fatores internos e externos. Para cada fator externo, especialistas da área atribuem pesos, que variavam de zero $(0,0)$ a um $(1,0)$, considerando o grau de importância de cada fator, sendo que o somatório total dos pesos atribuídos não deve ser superior ao valor de um $(1,0)$. Para avaliação de desempenho, consideram-se como respostas, que são fornecidas nas entrevistas, valores variando de 1-4.

A partir da definição das Forças e Fraquezas, Ameaças e Oportunidades do uso e comercialização dos produtos florestais não-madeireiros, foi possível realizar uma avaliação dos cenários, perspectivas, desafios e a definição das melhores estratégias para a consolidação do modelo de manejo sustentável dos produtos florestais não-madeireiros. A interpretação das matrizes de fatores internos e externos segue o que foi apresentado por Salzmann (2009): pontuações totais bem abaixo de 2,5 indicaram uma organização fraca internamente. Assim, para este estudo, se as pontuações totais sumarizarem abaixo de 2,5 , as comunidades da APA 
não serão consideradas internamente fortes para o desenvolvimento de atividades relacionadas ao uso e comercialização de produtos florestais não-madeireiros, sendo o contrário também verdadeiro.

Segundo Chitsondzo e Silva (2013), para reduzir a subjetividade da análise SWOT, faz-se a quantificação das forças e fraquezas, usando a matriz de avaliação de fatores internos - IFE -Internal Factor Evaluation. Do mesmo modo, faz-se a quantificação das oportunidades e ameaças, usando a matriz de avaliação de fatores externos - EFE -External Factor Evaluation. Essas matrizes - de fatores internos e externos - servem como forma de possibilitar a proposição de um conjunto estratégico capaz de (1) fortalecer as relações produtivas locais, (2) superar os principais entraves econômicos e, principalmente, (3) fundamentar um conjunto de planos de ação que, uma vez implementado, possibilite estruturar ações conjuntas e acompanhar os resultados obtidos de forma a corrigir cursos de ação e ajustar novas proposições (MATTOS et al., 2011).

\section{Resultados e discussão}

\section{Identificação e caracterização dos produtos não-madeireiros}

$\mathrm{Na}$ área de estudo, que abrangeu as quatro unidades de gestão da APA de Guaratuba inseridas nos limites do município de Guaratuba, foi identificada a utilização de um total de cinco produtos florestais não-madeireiros extraídos pelas famílias agricultoras rurais de florestas nativas. A Tabela 2 apresenta o nome popular, nome científico, a família, a categoria de uso e a parte da planta utilizada de cada produto identificado.

\section{Tabela 2 - Produtos não-madeireiros identificados na APA de Guaratuba}

Table 2 - Non-wood products identified in Guaratuba's EPA

\begin{tabular}{lcllcr}
\hline Nome Popular & Nome científico & Família & Categoria de uso & Parte da planta & Tipo \\
\hline Cipó-Preto & $\begin{array}{c}\text { Philodendron } \\
\text { melanorrhizum }\end{array}$ & Araceae & Ornamental & Raiz & Nativa \\
Cipó-Timbopeva & Philodendron spp & Araceae & Ornamental & Raiz & Nativa \\
Musgo, Veludo & Sphagnum spp & Rutaceae & Ornamental & Parte aérea & Nativa \\
Guaricana & Geonomagamiova & Arecaceae & Ornamental & Folha & Nativa \\
Palmeira Juçara & Euterpe edulis & Arecaceae & Alimentício & Fruto & Nativa \\
\hline
\end{tabular}

Fonte: Autores (2018)

Do total de 70 famílias entrevistadas, $80 \%$ (56 famílias) fazem uso e comercialização de produto florestal não madeireiro, sendo que $66,07 \%$ extraem de florestas nativas, $29,31 \%$ produzem em florestas plantadas e $33,93 \%$ utilizam de ambas, nativas e plantadas. A participação das famílias na extração e beneficiamento dos produtos não-madeireiros nativos é apresentada na Tabela 3 por unidade de gestão.

É possível observar que a totalidade dos extratores de musgo pertence às comunidades da Linha Morro Grande. Já os coletores de folha de Guaricana predominam nas comunidades da Linha Caovi-Limeira e Estrada do Castelhano. 


\section{Tabela 3 - Número de famílias extrativistas por tipo de produto não madeireiro na APA de Guaratuba}

Table 3 - Number of extractive families by type of non-wood products

\begin{tabular}{lcccccccc}
\hline \multirow{2}{*}{ Produto } & \multicolumn{2}{c}{ Caovi-Limeira } & \multicolumn{2}{c}{$\begin{array}{c}\text { Morro } \\
\text { Grande }\end{array}$} & \multicolumn{2}{c}{$\begin{array}{c}\text { Estrada do } \\
\text { Castelhano }\end{array}$} & \multicolumn{2}{c}{$\begin{array}{c}\text { Baia de } \\
\text { Guaratuba }\end{array}$} \\
\cline { 2 - 9 } & Abs. & $\%$ & Abs. & $\%$ & Abs. & $\%$ & Abs. & $\%$ \\
\hline Cipó-Preto & 3 & 23,1 & 8 & 61,5 & 0 & 0 & 2 & 15,4 \\
Cipó-Timbopeva & 1 & 100,0 & 0 & 0 & 0 & 0 & 0 & 0 \\
$\begin{array}{l}\text { Musgo } \\
\text { Folha de }\end{array}$ & 0 & 0 & 17 & 100,0 & 0 & 0 & 0 & 0 \\
Guaricana & 10 & 66,6 & 0 & 0 & 4 & 26,6 & 1 & 6,8 \\
Fruto da Juçara & 2 & 66,7 & 1 & 33,3 & 0 & 0 & 0 & 0 \\
\hline
\end{tabular}

Fonte: Autores (2018)

Esse fato ocorre, principalmente, devido aos diferentes tipos de relevo encontrados na APA de Guaratuba, pois as comunidades da Linha Caovi-Limeira e Estrada do Castelhano encontram-se no entorno e na encosta da Serra do Mar, com características favoráveis a dispersão da Guaricana. Já as comunidades da linha Morro Grande e a Baia de Guaratuba estão localizadas na porção litorânea da APA, especialmente em locais de solo arenoso úmido a encharcado e sem cobertura arbórea ("brejos de restinga”) (NEGRELLE et al., 2014), o que favorece o surgimento do musgo.

Por outro lado, devido à característica de hemiepífita do gênero Philodendron, ao qual pertence o cipó-preto e o cipó-timbopeva, a extração desses produtos não está vinculada a um tipo específico de relevo, não sendo realizada apenas na Estrada do Castelhano. Os produtos extraídos de florestas nativas são apresentados na Tabela 4 em termos de quantidade retirada do produto por unidade de gestão.

Conforme relato dos entrevistados, é possível verificar que os coletores não possuem conhecimento da quantidade ideal de retirada do produto. Na extração das folhas de Guaricana, por exemplo, alguns coletores relataram que retiravam três folhas por árvore e que voltam dentro de 2 (dois) meses para coletar novas folhas na mesma árvore. Outros relataram que voltavam apenas depois de 4 (quatro) meses para que a planta possa se regenerar. Quanto aos métodos de cultivo, apenas dois entrevistados relataram a tentativa de plantar a Guaricana por semeadura, no entanto os procedimentos não obtiveram sucesso.

No caso do musgo, alguns entrevistados relataram que está cada vez mais difícil encontrar o produto, pois, segundo os coletores, áreas com florestas plantadas de pinus dificultam a proliferação do musgo, principalmente devido à necessidade de ambientes úmidos. Assim, os coletores de musgo têm retirado cada vez mais indivíduos, sendo relatado como práticas de "tirar tudo". Por outro lado, a coleta de cipós é uma prática de manejo empírica aos extrativistas, estes relataram que, quando encontram as raízes, retiram apenas "a mãe", ou seja, apenas as raízes maduras, deixando "os filhos" para nova retirada. No entanto, os coletores de cipó estão adentrando os limites dos Parques para coleta dos produtos, embora o regime de Proteção integral dos parques não permita a retirada de subprodutos do seu interior. Observa-se também que com a criação de parques nos limites da APA, as famílias estão ficando com áreas mais restritas para expandir suas coletas. Essa limitação de área para expansão da atividade e a redução da ocorrência afeta diretamente o preço dos produtos. A Tabela 5 apresenta o preço médio pago ao produtor pelo produto florestal não madeireiro extraídos das florestas nativas. 
Tabela 4 - Quantidade de produto florestal não madeireiro extraído das florestas nativas, no ano de 2018, nas diversas localidades, na APA de Guaratuba

Table 4 - Quantity of non-timber forest product taken from native forests, in 2018, in the various localities

\begin{tabular}{|c|c|c|c|c|c|}
\hline \multirow{2}{*}{ Produto } & Caovi-Limeira & Morro Grande & $\begin{array}{l}\text { Estrada do } \\
\text { Castelhano } \\
\end{array}$ & $\begin{array}{c}\text { Baia de } \\
\text { Guaratuba }\end{array}$ & \multirow{2}{*}{ Total } \\
\hline & $\begin{array}{c}\text { Quantidade } \\
\text { retirada }\end{array}$ & $\begin{array}{c}\text { Quantidade } \\
\text { retirada }\end{array}$ & $\begin{array}{c}\text { Quantidade } \\
\text { retirada }\end{array}$ & $\begin{array}{c}\text { Quantidade } \\
\text { retirada }\end{array}$ & \\
\hline Cipó-Preto & $3.000 \mathrm{~kg}$ & $4.080 \mathrm{~kg}$ & 0 & $100 \mathrm{~kg}$ & $7.900 \mathrm{~kg}$ \\
\hline Cipó-Timbopeva & $3.360 \mathrm{~kg}$ & 0 & 0 & 0 & $3.360 \mathrm{~kg}$ \\
\hline Musgo & 0 & 0 & $42.232 \mathrm{sc}$ & 0 & $42.232 \mathrm{sc}$ \\
\hline Folha de Guaricana & $\begin{array}{l}3.378 .000 \\
\text { folhas }\end{array}$ & 0 & $\begin{array}{l}1.440 .000 \\
\text { folhas }\end{array}$ & 0 & $\begin{array}{l}4.818 .000 \\
\text { folhas }\end{array}$ \\
\hline Fruto da Juçara & $300 \mathrm{~kg}$ & 0 & 0 & 0 & $300 \mathrm{~kg}$ \\
\hline
\end{tabular}

Fonte: Autores (2018)

Em que: $\mathrm{kg}$ = quilograma e sc = saco.

Tabela 5 - Preço médio pago ao produtor pelo produto florestal não madeireiro extraídos das florestas nativas, na APA de Guaratuba

Table 5 - Average price paid to the producer for the non-timber forest product extracted from the native forests

\begin{tabular}{lcc}
\hline \multicolumn{1}{c}{ Produto } & Preço pago ao produtor & Preço considerado justo \\
\hline Cipó-Preto & $\mathrm{R} \$ 1,00 / \mathrm{kg}$ & $\mathrm{R} \$ 1,50 / \mathrm{kg}$ \\
Cipó-Timbopeva & $\mathrm{R} \$ 8,00 /$ vassoura & - \\
Musgo & $\mathrm{R} \$ 6,56 / \mathrm{saco}$ & $\mathrm{R} \$ 10,00 / \mathrm{saco}$ \\
Folha de Guaricana & $\mathrm{R} \$ 0,63 /$ maço $(10$ folhas $)$ & $\mathrm{R} \$ 1,00 /$ maço (10 folhas $)$ \\
Fruto da Juçara & $\mathrm{R} \$ 1,00 / \mathrm{kg}$ & - \\
\hline
\end{tabular}

Fonte: Autores (2018) 
O tempo médio gasto pelos coletores para extrair o cipó-preto é de 8 horas por dia, sendo a distância média percorrida até encontrar a raiz de $1,3 \mathrm{~km}$, devido ao árduo trabalho, o preço de venda do cipó-preto é considerado injusto por $100 \%$ das famílias. A coleta do cipó-timbopeva para fabricação da vassoura é considerada de difícil acesso pelo produtor, sendo que a coleta é realiza em terra própria e de terceiros, com tempo gasto de até 2 horas para encontrar a raiz. A venda é realizada diretamente no mercado varejista, por $\mathrm{R} \$ 8,00$ a unidade, preço considerado justo pelo produtor, uma vez que a quantidade de vassoura produzida é programada mensalmente com o varejista.

A dinâmica de comercialização da folha de Guaricana indica um preço médio de $\mathrm{R} \$ 0,63$ recebido por maço (10 folhas), variando de $\mathrm{R} \$ 0,50 /$ maço a $\mathrm{R} \$ 1,00 /$ maço. Foi possível observar que o valor varia de acordo com a distância da comunidade de um centro urbano. A evidente redução na faixa de ocorrência do musgo e o aumento no número de pessoas que exploram a área têm uma influência negativa na sustentabilidade da atividade. A declaração dos entrevistados em retirar todo musgo encontrado no local preocupa tanto com relação à ecologia da espécie quanto à capacidade das gerações futuras em satisfazer suas necessidades.

Nas entrevistas, foi constatado que três produtores permitem a entrada de terceiros para retirada dos frutos do palmito juçara. A média de retirada por ano é de 300 quilos a um preço pago ao dono da área de $\mathrm{R} \$ 1,00 / \mathrm{kg}$. Atualmente, existe no município de Garuva uma indústria de alimentos que produz polpa do fruto da Juçara e compra fruto das comunidades do seu entorno, sendo o preço pago ao coletor por de $\mathrm{R} \$ 1,30 / \mathrm{kg}$.

\section{Fatores limitantes dos sistemas de produção e comercialização dos produtos extraídos de florestas nativas}

A análise SWOT realizada na área de estudo teve como foco os produtores rurais que realizam extrativismo em florestas nativas dos produtos apresentados na Tabela 4. A avaliação da Matriz dos Fatores Internos (Tabela 6) apresenta a avaliação quantitativa dos fatores internos identificados na análise SWOT, fortalezas e fraquezas. A pontuação total ponderada dos fatores internos foi de 2,53.

É possível observar que os Fatores Críticos de Sucesso, das matrizes interna e externa, diferem daqueles apresentados na Tabela 1, isso leva a perceber que os atores da área em estudo apresentam perspectivas diferentes das apresentadas pela literatura. Assim, é possível identificar fatores divergentes do ponto de vista da literatura, dos atores comunitários e dos pesquisadores, como por exemplo, o fator Liberdade no trabalho, que aparece com importante peso por parte dos comunitários, no entanto apresenta baixo desempenho no ponto de vista dos pesquisadores.

O planejamento estratégico para o desenvolvimento da atividade extrativista na região deve explorar as fortalezas que obtiveram maior escore como a manutenção e resgate do conhecimento tradicional e a possibilidade de a atividade não madeireira ser um incremento de renda para as famílias tradicionais. Essas fortalezas devem ser estimuladas, mediante a redução ou eliminação das fraquezas, como a venda do produto com pouco/nenhum valor agregado. Como alternativa, deve-se buscar cursos de capacitação com entidades locais, a fim de aumentar o preço pago pelo produto ao longo da cadeia de valor e fortalecer as comunidades para diminuir a dependência do atravessador.

O fator de falta de titularidade da terra deve ser eliminado, por meio de Políticas de Regularização Fundiária e alternativas, junto aos instrumentos de política agrária para melhorar o nível de organização coletiva da comunidade. Em conjunto com instituições de ensino e de pesquisa, proporcionar a criação de um banco de dados com todas as pesquisas realizadas na região, a fim de determinar as demandas de estudos futuros e suprir a falta de conhecimento sobre a ecologia das espécies da região. 


\section{Tabela 6 - Matriz de fatores internos da análise SWOT com influência nos sistemas de produção e comercialização dos produtos extraídos de florestas nativas}

Table 6 - SWOT analysis internal factors matrix with influence on the production and marketing systems of products extracted from native forests

\begin{tabular}{|c|c|c|c|}
\hline Fatores Críticos de Sucesso & Peso & Desempenho & Resultado \\
\hline \multicolumn{4}{|c|}{ Fortalezas } \\
\hline Conhecimento tradicional; & 0,175 & 3,13 & 0,55 \\
\hline Uso exclusivo da Mão de Obra familiar; & 0,025 & 3,88 & 0,19 \\
\hline Possibilidade de incremento de renda; & 0,100 & 2,26 & 0,23 \\
\hline Pode contar com a ajuda de vizinhos (Guajus); & 0,025 & 1,40 & 0,04 \\
\hline Liberdade no trabalho; & 0,050 & 0,52 & 0,03 \\
\hline Sentimento de integração com a floresta. & 0,025 & 3,67 & 0,09 \\
\hline \multicolumn{4}{|c|}{ Fraquezas } \\
\hline Falta de união da comunidade (Associativismo); & 0,150 & 2,59 & 0,39 \\
\hline Única fonte de renda; & 0,075 & 0,69 & 0,05 \\
\hline Venda do produto com pouco/nenhum valor agregado; & 0,150 & 3,21 & 0,48 \\
\hline Alta competição pelo recurso; & 0,075 & 0,66 & 0,05 \\
\hline Falta de conhecimento sobre a ecologia das espécies; & 0,075 & 3,78 & 0,38 \\
\hline Falta de titularidade da terra; & 0,025 & 2,59 & 0,06 \\
\hline Trabalho pesado sem direito trabalhista. & 0,025 & 1,04 & 0,00 \\
\hline Total & 1,000 & & 2,53 \\
\hline
\end{tabular}

Fonte: Autores (2018)

A avaliação da Matriz dos Fatores Externos (Tabela 7) apresenta a avaliação quantitativa dos fatores externos identificados na análise SWOT: oportunidades e ameaças. A pontuação total ponderada dos fatores externos foi de 2,69.

O escore total para os fatores externos foi maior que a média 2,5 indicada pelo método da matriz de avaliação dos fatores externos. Isso indica que a área de estudo dispõe de características para desenvolver as atividades extrativistas de produtos florestais não-madeireiros extraídos de florestas nativas que respondem melhor às oportunidades, sendo menos sensíveis às ameaças. A área está localizada em um ambiente com abundantes oportunidades e potencial de explorar suas potencialidades, tanto em mercados locais, como em outros centros urbanos, uma vez que a maior parte da produção é comercializada para outros municípios ou estados.

Para o planejamento estratégico, deve-se ter em mente a dominância de agricultores familiares como forma de abordagem em políticas públicas em que o acesso a essas políticas públicas, voltadas para o fortalecimento da ag ricultura familiar, constitui-se de grande importância para a reprodução socioeconômica das famílias. Além disso, incentivar a diversificação da propriedade e/ou o desenvolvimento de formas alternativas de produção (agroecologia e agricultura orgânica, por exemplo) - ou seja, atividades mais compatíveis com o tamanho das propriedades e que permitam a diversificação das fontes de rendas e inseririam as famílias de forma diferenciada no mercado. 


\section{Tabela 7 - Matriz de fatores externos da análise SWOT com influência nos sistemas de produção e comercialização dos produtos extraídos de florestas nativas}

Table 7 - SWOT analysis external factors matrix with influence on the production and marketing systems of products extracted from native forests

\begin{tabular}{l|lll}
\hline \multicolumn{1}{c|}{ Fatores Críticos de Sucesso } & Peso & Desempenho & Resultado \\
\hline \multicolumn{2}{c}{ Oportunidade } \\
\hline Dominância de agricultores familiares; & 0,100 & 3,56 & 0,36 \\
Possibilidade de sucessão familiar de terras; & 0,050 & 2,48 & 0,12 \\
Mais de 50\% da área coberta por floresta nativa; & 0,150 & 2,23 & 0,33 \\
Presença do intermediário. & 0,075 & 3,56 & 0,27 \\
\hline \multicolumn{1}{c|}{ Ameaças } & & & 0,01 \\
\hline Falta de periodicidade do atravessador; & 0,025 & 0,31 & 0,47 \\
Escassez do PFNM; & 0,150 & 3,11 & 0,30 \\
Baixo Preço pago pelo produto; & 0,100 & 2,95 & 0,38 \\
Falta de assistência técnica; & 0,125 & 3,02 & 0,09 \\
Falta de capacitação para boas práticas de manejo; & 0,025 & 3,78 & 0,16 \\
Dificuldade no acesso aos PFNM; & 0,050 & 3,12 & 0,18 \\
Dificuldade no acesso ao crédito rural; & 0,050 & 3,56 & 0,01 \\
Proibição dos proprietários à entrada dos extrativistas; & 0,050 & 0,18 & 0,03 \\
Falta de diálogo/informação com os órgãos ambientais. & 0,050 & 0,57 \\
\hline Total & 1,000 & & 2,69 \\
\hline
\end{tabular}

Fonte: Autores (2018)

A presença do intermediário aparece como fator de oportunidade devido à dificuldade de acesso da maioria das comunidades aos centros urbanos, no entanto deve ser encarado como variável transitória. A crescente preocupação com cadeias mais éticas e justas em seu percurso até o comprador final deve ser um fator importante na elaboração de contratos diretos com as empresas compradoras dos produtos. Essa possibilidade de diminuição da dependência do atravessador deve ser trabalhada juntamente com o fortalecimento da comunidade e a organização em cooperativas que busquem agregar valor aos seus produtos.

A falta de assistência técnica foi definida tanto pelos entrevistados quanto pelos especialistas como o fator de maior importância dentre as ameaças. Os serviços públicos de ATER devem focalizar em atividades econômicas prioritárias compatíveis com a região, obedecendo às vocações locais, de maneira que todos os produtores rurais de base familiar tenham acesso a esse serviço com qualidade e efetividade, fato que atualmente não ocorre, visto que apenas os bananicultores contam com esse serviço. 


\section{Conclusão}

A avaliação da matriz SWOT permite indicar que a região de estudo se mostra adequada para o desenvolvimento de atividades com produtos florestais não-madeireiros, tanto internamente quanto externamente. Como principais fatores limitantes para consolidação dos sistemas de produção, apresentam-se a venda do produto com pouco ou nenhum valor agregado e a escassez dos produtos florestais não madeireiros.

Como cada comunidade é heterogênea no seu sistema de produção e comercialização de produtos florestais não-madeireiros, recomenda-se que o planejamento e a organização das atividades devem ser específicos para cada unidade de gestão.

$\mathrm{O}$ uso e a comercialização dos produtos florestais não-madeireiros estão presentes em todas as comunidades estudadas e devem ser considerados como elementos-chave na diversificação e possibilidade de aumento de renda das comunidades da região. Em uma área onde existe a comercialização de produtos florestais não-madeireiros em todas as comunidades, não é possível que a atividade permaneça invisível em termos de regulamentação e formalização. A política de medo deve ser substituída por uma política de informação e de reconhecimento.

É preciso reconhecer as particularidades de cada região e definir as melhores estratégias de conservação produtiva para as comunidades. A formação das associações extrativistas, por meio de organização interna, instalação de infraestrutura social e comunitária e a melhoria da capacidade produtiva são ações indispensáveis para fortalecimentos das comunidades.

\section{Referências}

ANACLETO, A. et al. As relações entre extrativismo, justiça social e desenvolvimento sustentável em remanescentes de comunidades caiçaras inseridas em ambientes florestais no litoral sul do Estado do Paraná. In: CONGRESSO INTERNACIONAL DE ADMINISTRAÇÃO, 2007, Ponta Grossa. Anais [...]. Ponta Grossa: [s. n.], 2007.

BRITES, A. D.; MORSELLO, C. Monitoramento e avaliação de projetos de conservação baseados na comercialização de produtos florestais não madeireiros: qual é a abordagem mais adequada? In: ENCONTRO DA ASSOCIAÇÃO NACIONAL DE PESQUISA PÓS-GRADUAÇÃO EM AMBIENTE E SOCIEDADE, 4., 2008, Brasília. Anais [...]. Campinas: Associação Nacional de Pesquisa e Pós-Graduação em Ambiente e Sociedade, 2008.

CARVALHAES, M. A.et al. Produtos florestais madeireiros e não madeireiros da Mata Atlântica brasileira: oportunidades para a conservação e a restauração florestal. Florestar Estatístico, São Paulo, v. 11, n. 20, p. 9-17, jun. 2008.

CHITSONDZO, C. C. E.; SILVA, I. C. Quintais caseiros em Machipanda, distrito de Manica, Moçambique. Pesquisa Florestal Brasileira, Colombo, v. 33, n. 74, p. 127-135, abr./jun. 2013.

FERREIRA, M. R. Comunidades rurais de Guaratuba-Paraná: os limites e as possibilidades da opção extrativista como meio de vida no contexto do desenvolvimento rural sustentável. 2010. Tese (Doutorado em Agronomia) - Setor de Ciências Agrárias, Universidade Federal do Paraná, Curitiba, 2010.

MATTOS, C. A. C. de et al. Estratégias de planejamento a partir do diagnóstico rápido 
participativo e da análise SWOT: um estudo na comunidade de São Bento, Salinópolis - PA. Sociedade e Desenvolvimento Rural, [s. l.], v. 5, n. 2, dez. 2011.

NEGRELLE, R. R. B. et al. Extrativismo e comercialização de Sphagnum (veludo): características, implicações socioeconômicas e ecológicas e perspectivas. Revista Brasileira de Horitucultura Ornamental, São Paulo, v. 20, n. 1, p. 53-66, 2014.

OLIVEIRA, C. L. Um apanhado teórico-conceitual sobre a pesquisa qualitativa: tipos, técnicas e características. 4. ed. Paraná: [s.n.], 2009.

PARANÁ. Secretaria do Meio Ambiente e Recursos Hídricos. Área de Proteção Ambiental de Guaratuba. Curitiba, 2016. Disponível em: http://www.meioambiente.pr.gov.br/modules/ conteudo/conteudo.php? conteudo=121. Acesso em: 14 abr. 2016.

SAlZMAnN, A. M. Agroforestry systems in Cerro Azul (Brazil) and Dali (China): base for rural development and policy planning. 2009. Dissertação (Mestrado em Ciências Florestais Europeias) - Faculty of Forest and Environmental Sciences, University of Freiburg, Freiburg, 2009.

SONDA, C. Comunidades rurais tradicionais da área de proteção ambiental de Guaratuba: caracterização sócio-econômica e utilização dos recursos vegetais silvestres. 2002. Tese (Doutorado em Engenharia Florestal) - Setor de Ciências Agrárias, Universidade Federal do Paraná, Curitiba, 2002.

SOSMA e INPE. Fundação SOS Mata Atlântica; Instituto Nacional de Pesquisas Espaciais. Atlas dos remanescentes florestais da mata atlântica período 2012-2013. Relatório Técnico. São Paulo, 2014.

SILVEIRA-JUNIOR, W. J. da; BOTELHO, E. S. Turismo em áreas protegidas e inclusão social de populações tradicionais: um estudo de caso da Cooperativa de Ecoturismo de Guaraqueçaba (PR). Revista Brasileira de Ecoturismo, São Paulo, v. 4, n. 3, p. 441-462, 2011.

WALDHOFF, P. Resultados da avaliação do manejo florestal comunitário sobre os meios de vida de seus protagonistas: destaque para conservação ambiental em detrimento a produção e autonomia. 2014. Tese (Doutorado em Recursos Florestais) - Escola Superior de Agricultura Luiz de Queiroz, Universidade de São Paulo, Piracicaba, 2014. 